3RD INTERNATIONAL ELECTRONIC CONFERENCE ON ATMOSPHERIC SCIENCES

\title{
Winter atmospheric boundary layer observations over sea ice in the coastal zone of the Bothnian Bay (Baltic Sea)
}

Marta Wenta (University of Gdansk), David Brus (Finnish Meteorological Institute), Konstantinos Doulgeris (Finnish Meteorological Institute), Ville Vakkari (Finnish Meteorological Institute), Agnieszka Herman (University of Gdansk)

martawentaegmail.com

sea ice interictiond oceanic

atmosphery layers" №.

2018/31/B/ST10/00195/

(benal Research 


\section{Haiuloto}

A tmospheric

Observations over

S ea ice

\section{HAOS}

\section{February - 2 March 2020}

TOTAL NUMBER OF 27

FIXED WING UAV AND 4

MULTIROTOR FLIGHTS. 


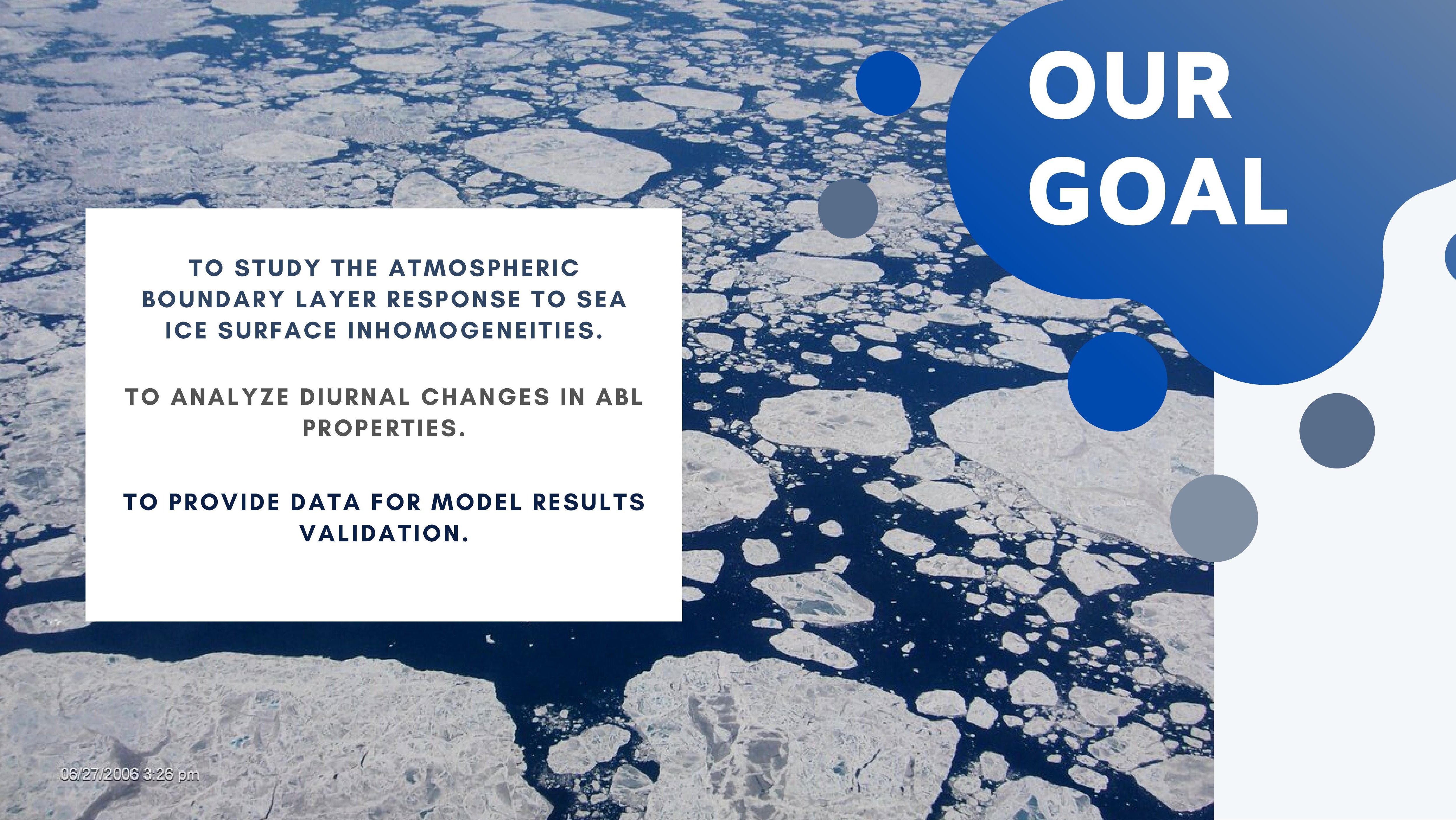




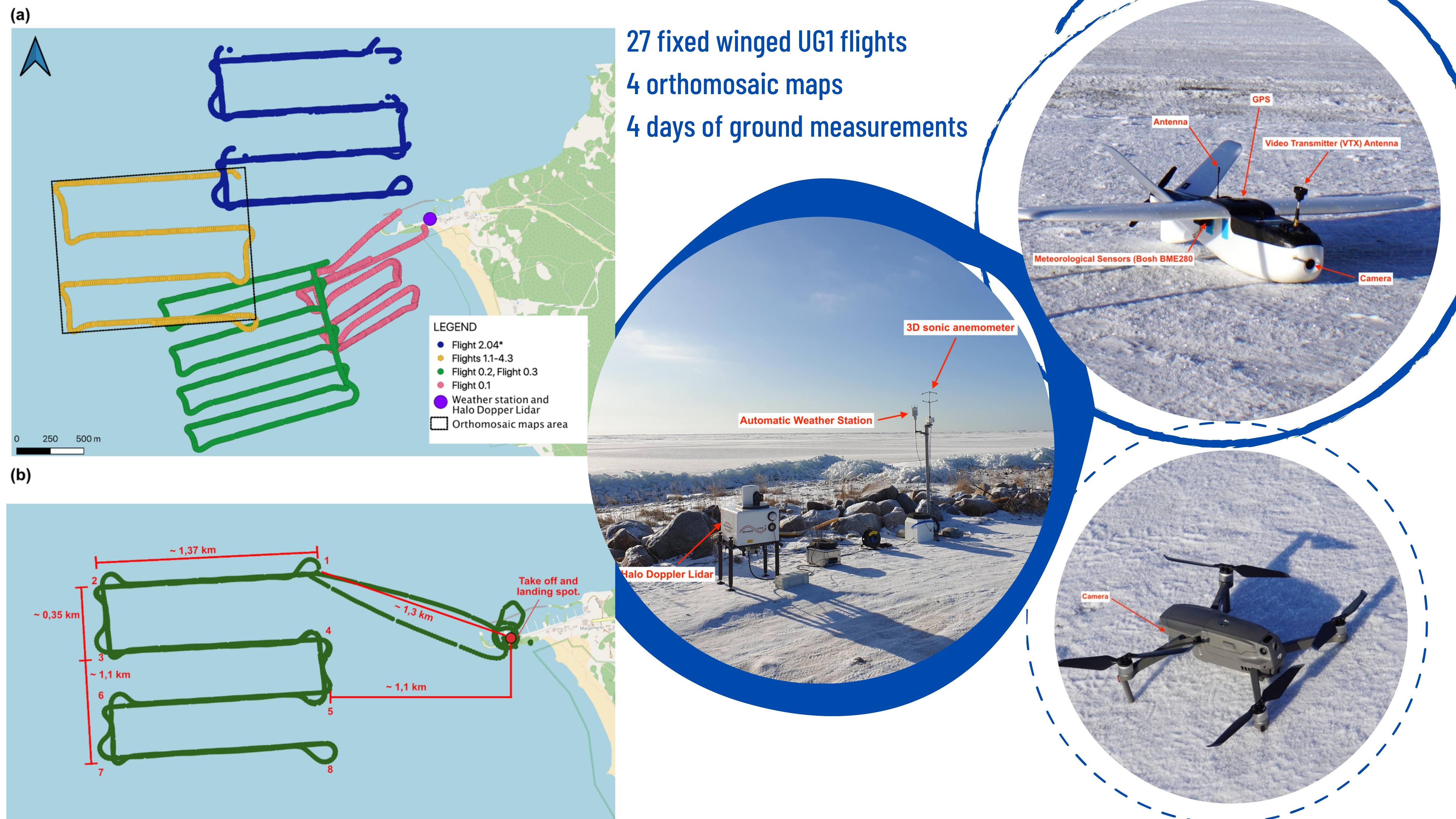



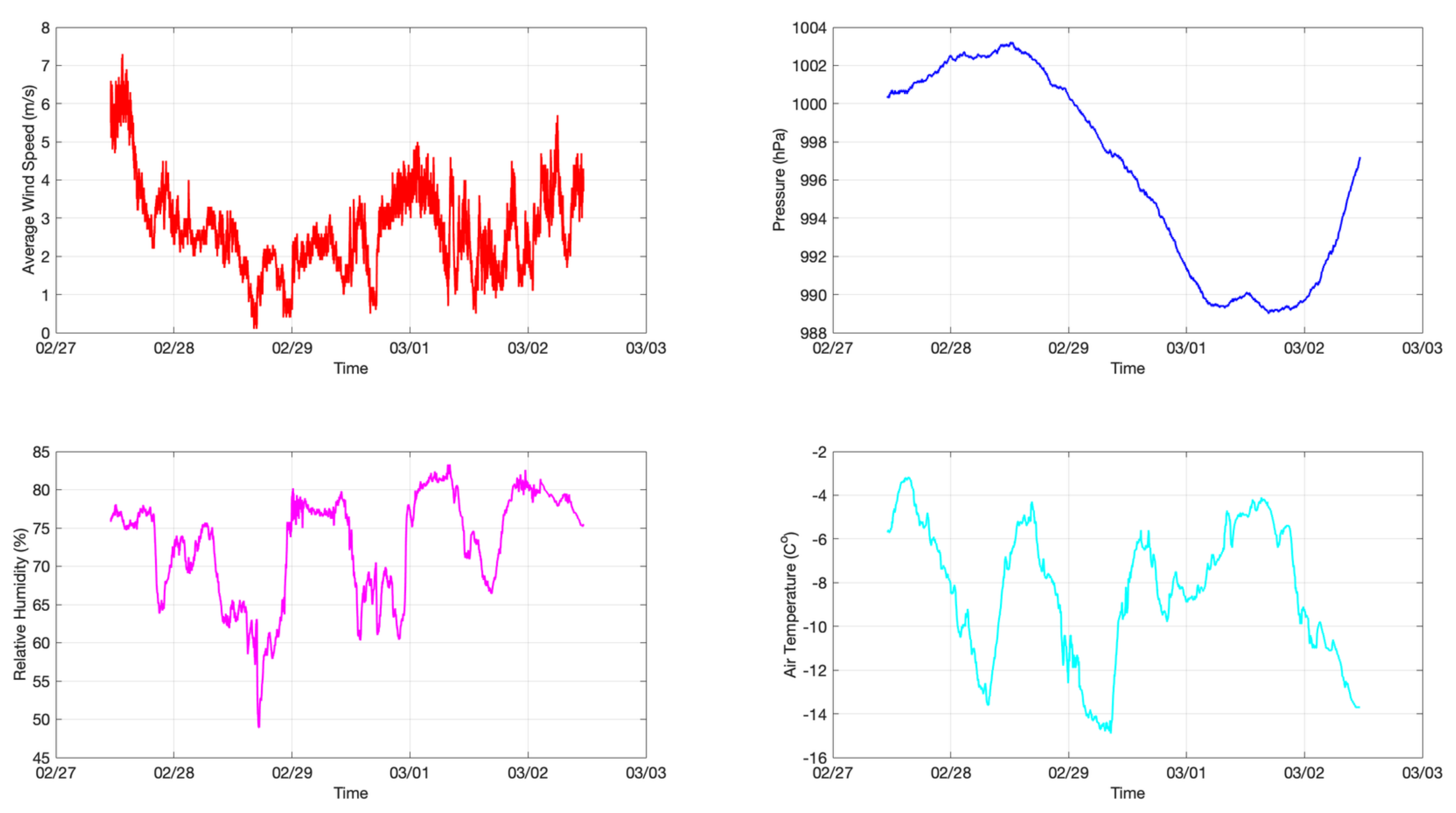


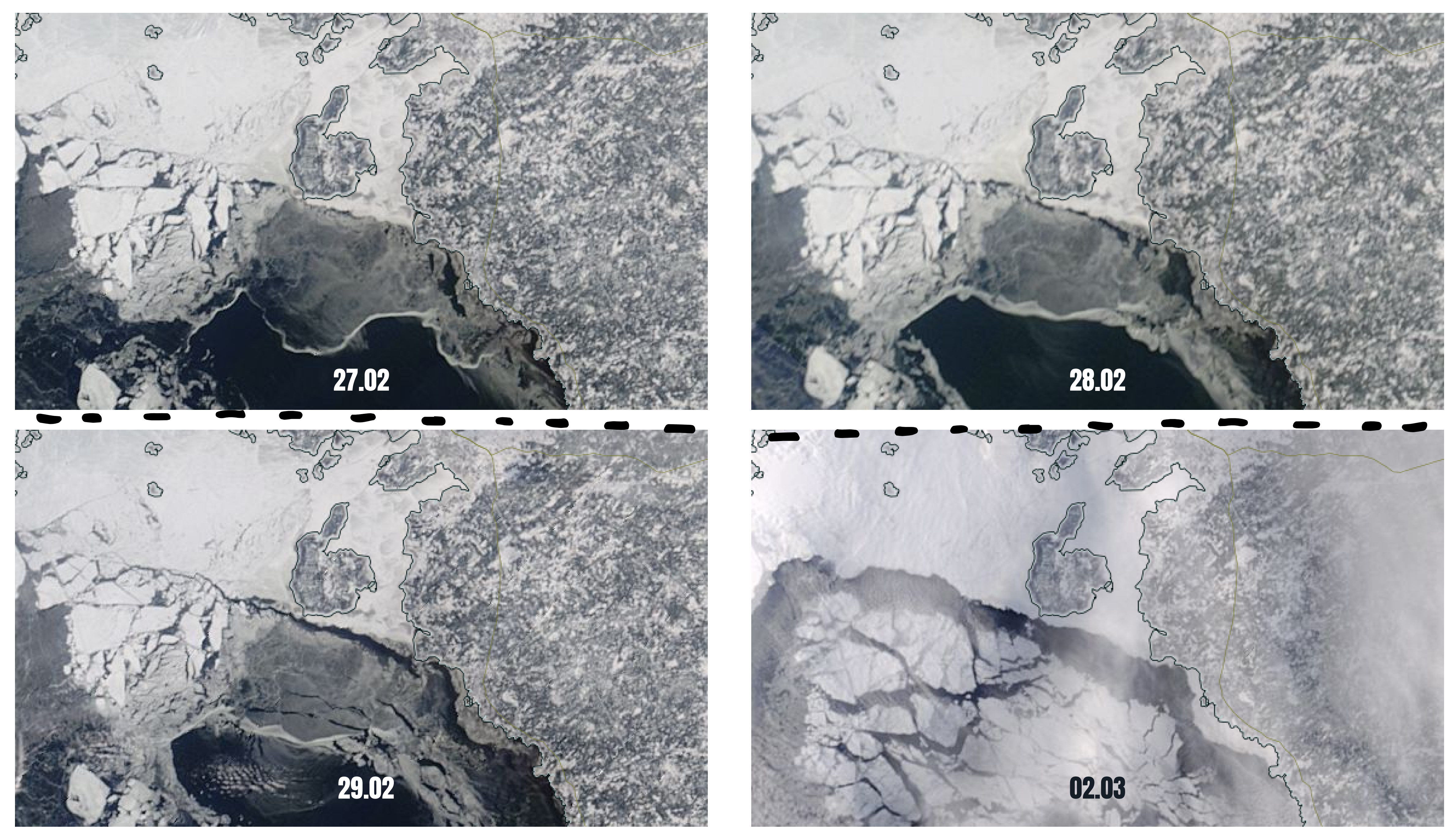




\section{UGI UAV}

AUTOMATIC WEATHER

STATION

3D

ANENOMETER

MEASURED PROPERTIES
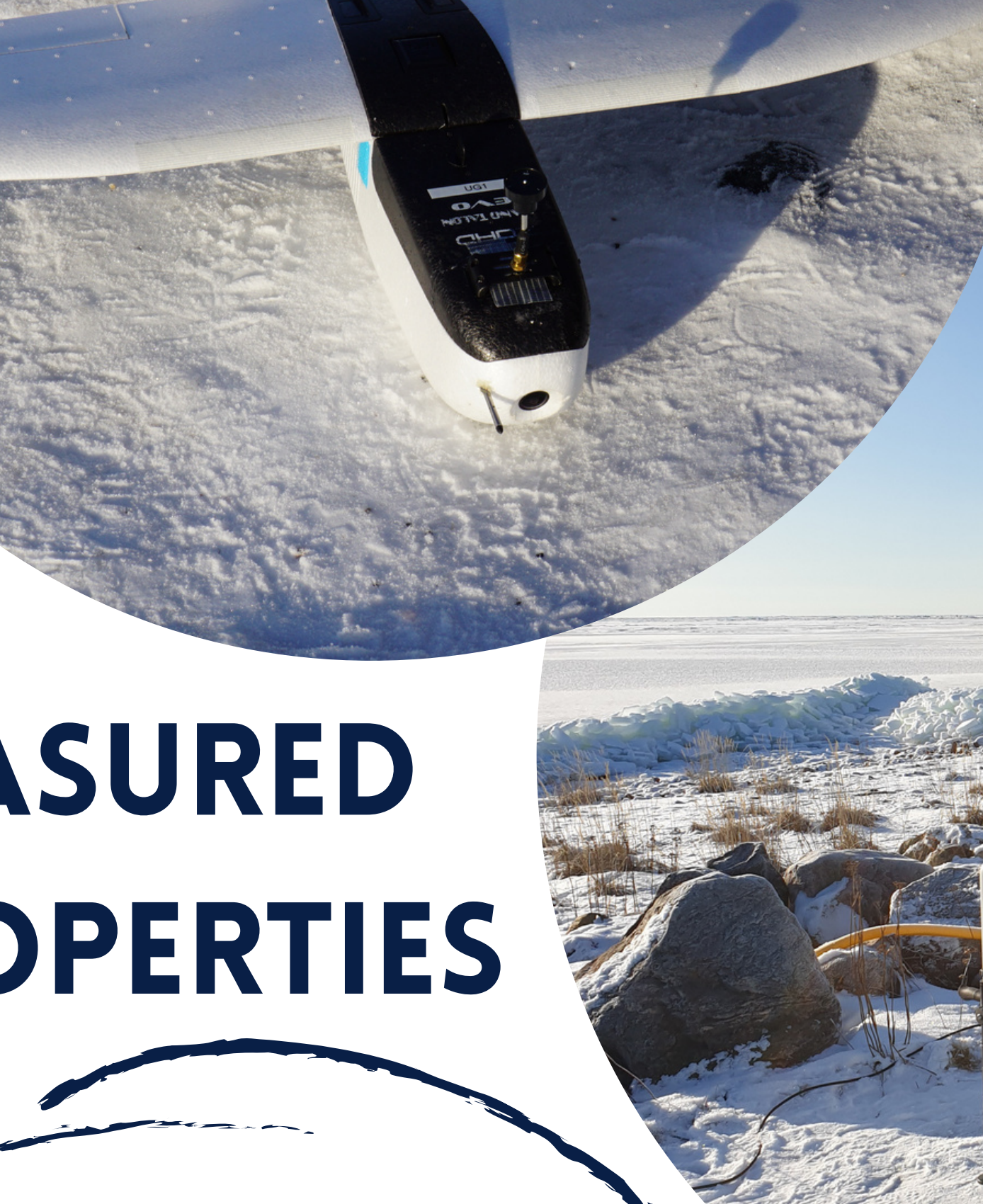

. ,
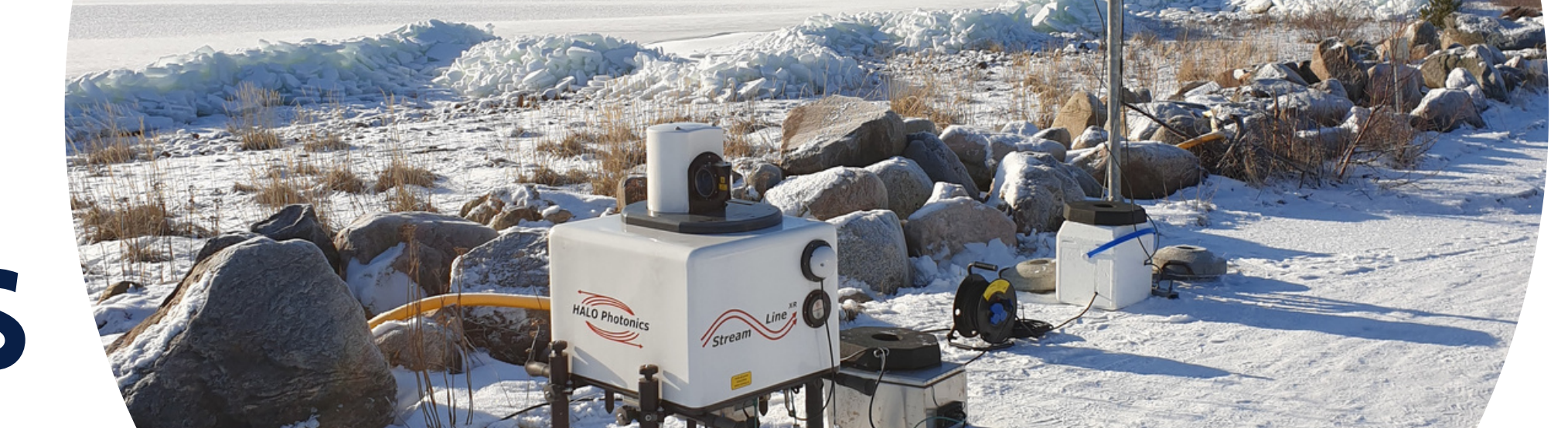

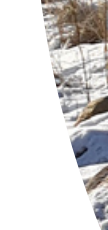

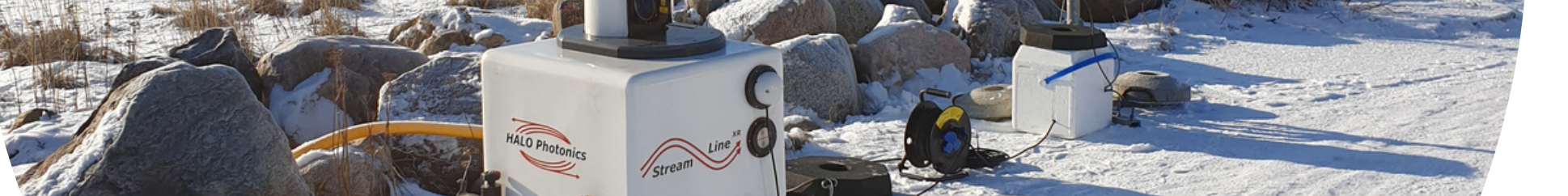
.

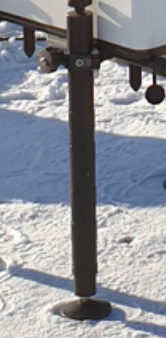

HALO DOPPLER LIDAR air temperature relative humidity air pressure

wind speed wind direction air temperature relative humidity air pressure precipitation

u, v, w wind components and acoustic temperature in $10 \mathrm{hz}$ resolution

horizontal wind speed and direction TKE dissipation rate turbulence proxy 


\section{SENTINEL-1 SYNTHETIC APERTURE RADAR (SAR)}
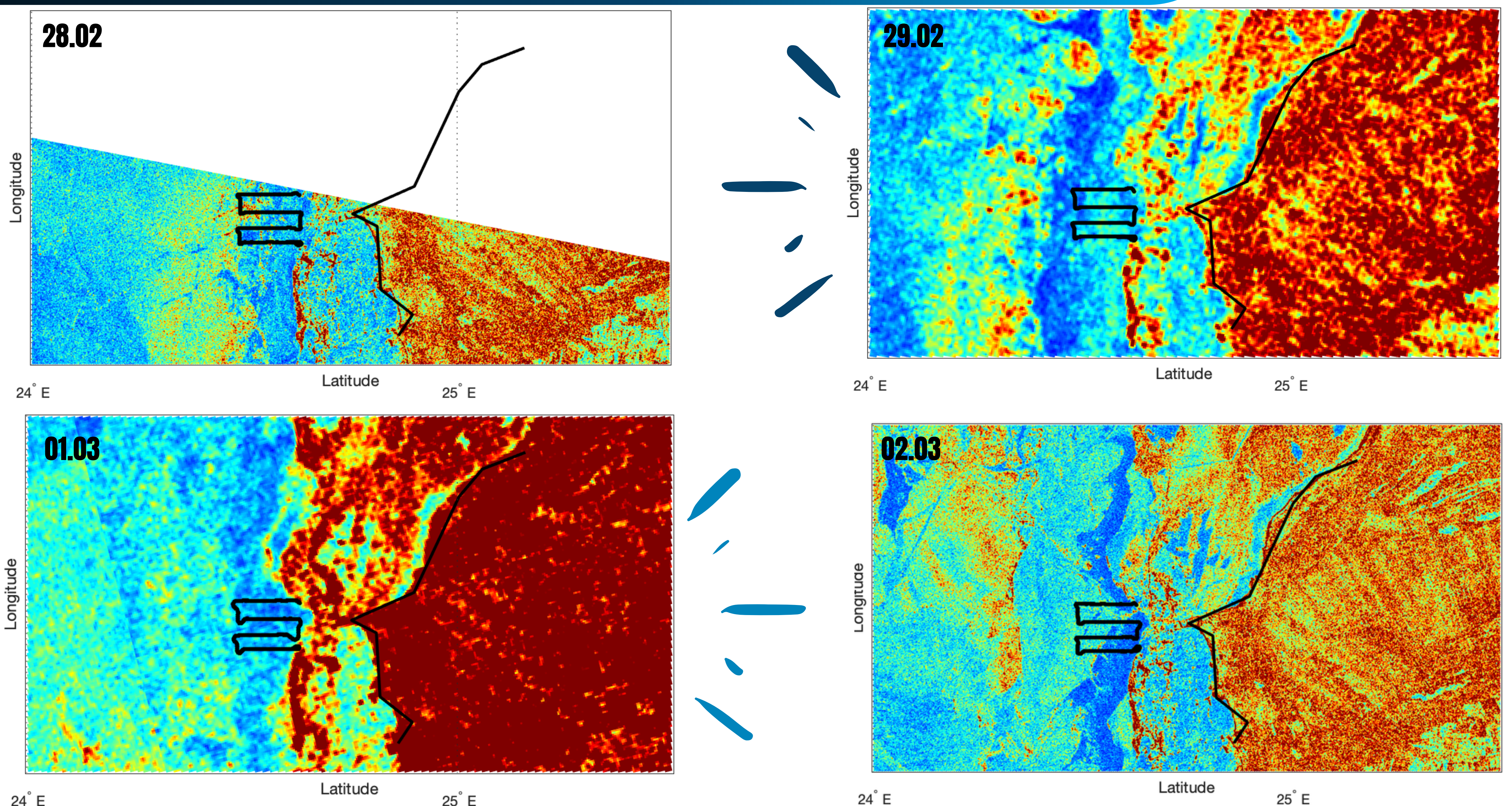

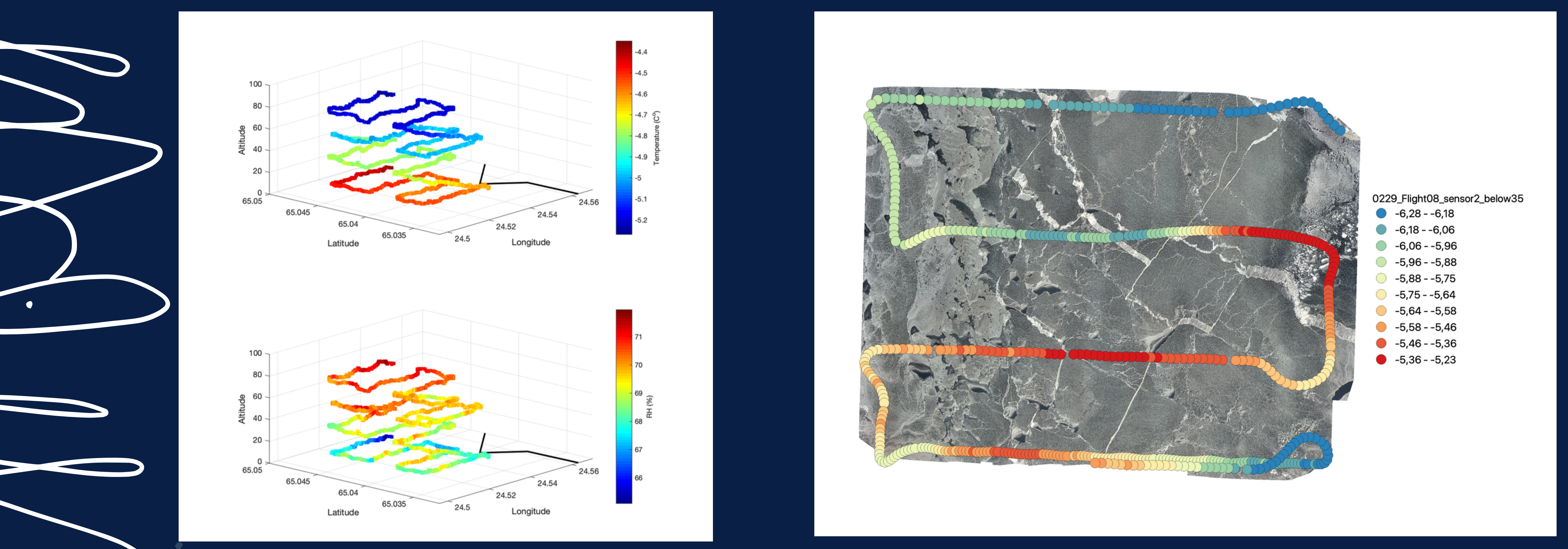

\section{RESULTS}

Presented dataset gives us a thorough description of atmospheric conditions over newly formed sea ice near Hailuoto island.

Detailed orthomosaic maps provide us an unique and extremely detailed view on the newly formed sea ice and its changes in the span of 4 days.

Considering the scarcity of recent ABL observations over diminishing sea ice over in the Bay of Bothnia presented dataset may be considered as valuable source of information and the basis for further studies on sea ice-atmospheric interactions in this region. 


\section{DATA+MODEL}

- COMPARE MEASUREMENTS WITH 1D MODEL RESULTS.

- ANALYZE WHETHER MODELS SIMULATES WELL THE DIURNAL CHANGES OF THE ABL ABOVE SEA ICE.

- VERIFY WHETHER THE ABL RESPONSE TO CHANGES IN SEA ICE SURFACE STRUCTURE (SNOW, ALBEDO) ARE REFLECTED IN MODEL RESULTS.

- IF THERE ARE DIFFERENCES, CHECK WHETHER THEY ARE CAUSED BY INSUFFICIENT PARAMETRIZATIONS OR INPUT CONDITIONS?

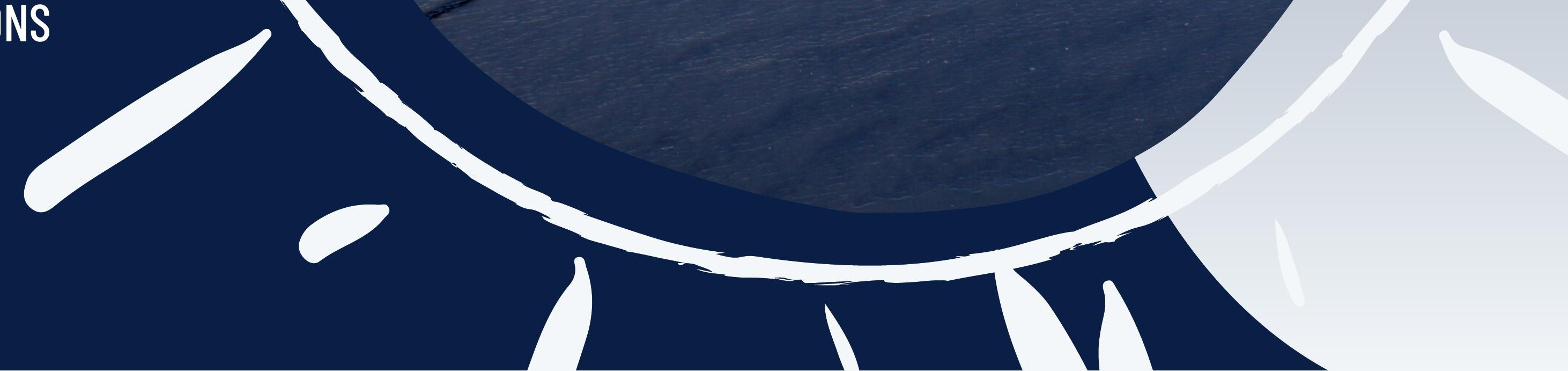



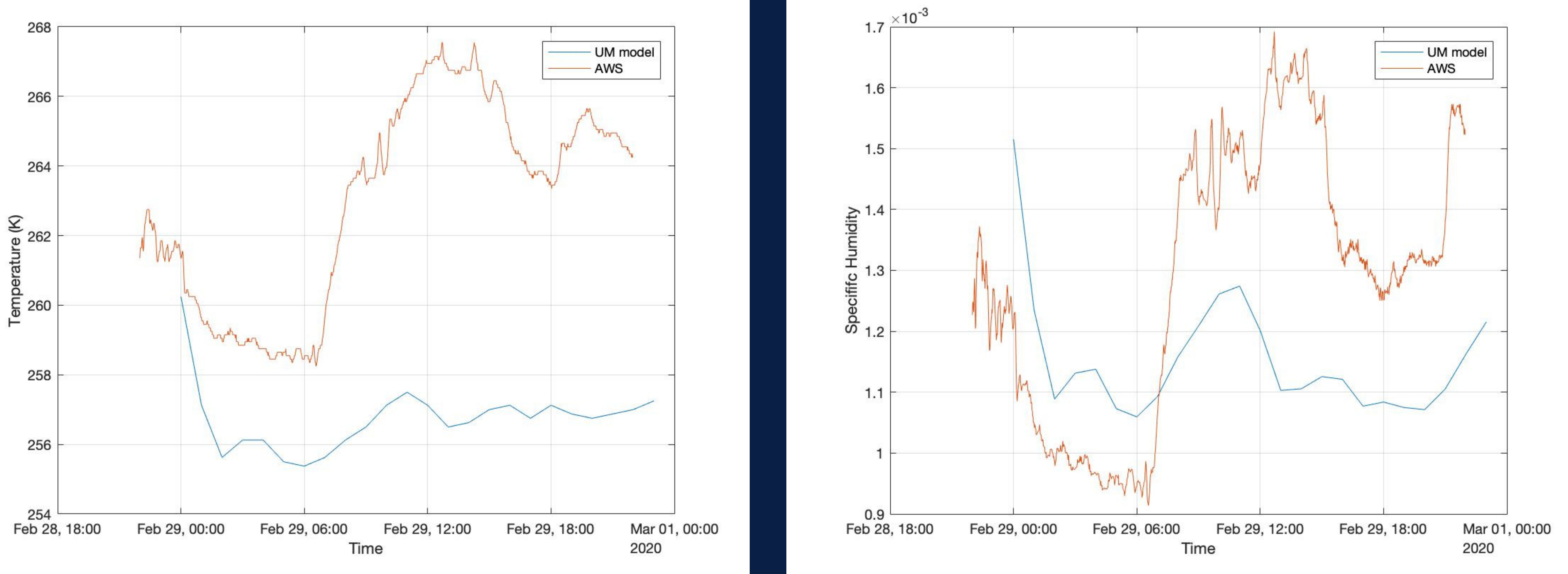

- HIGH RESOLUTION UM ICM MODEL (GRID SPACING OF 4KM) DOES NOT RESOLVE WELL THE TEMPORAL CHANGES OF TEMPERATURE AND SPECIFIC HUMIDITY THROUGHOUT THE TIME OF OUR MEASUREMENTS (AWS STATION) $\therefore \therefore \circ$
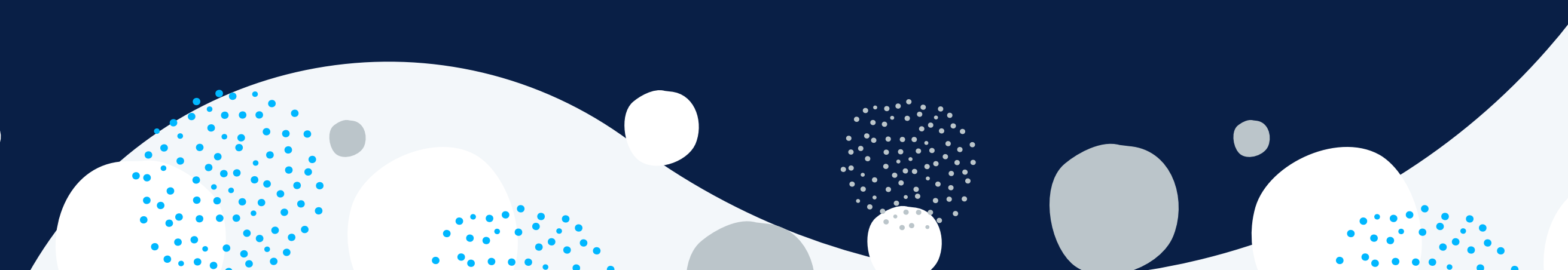

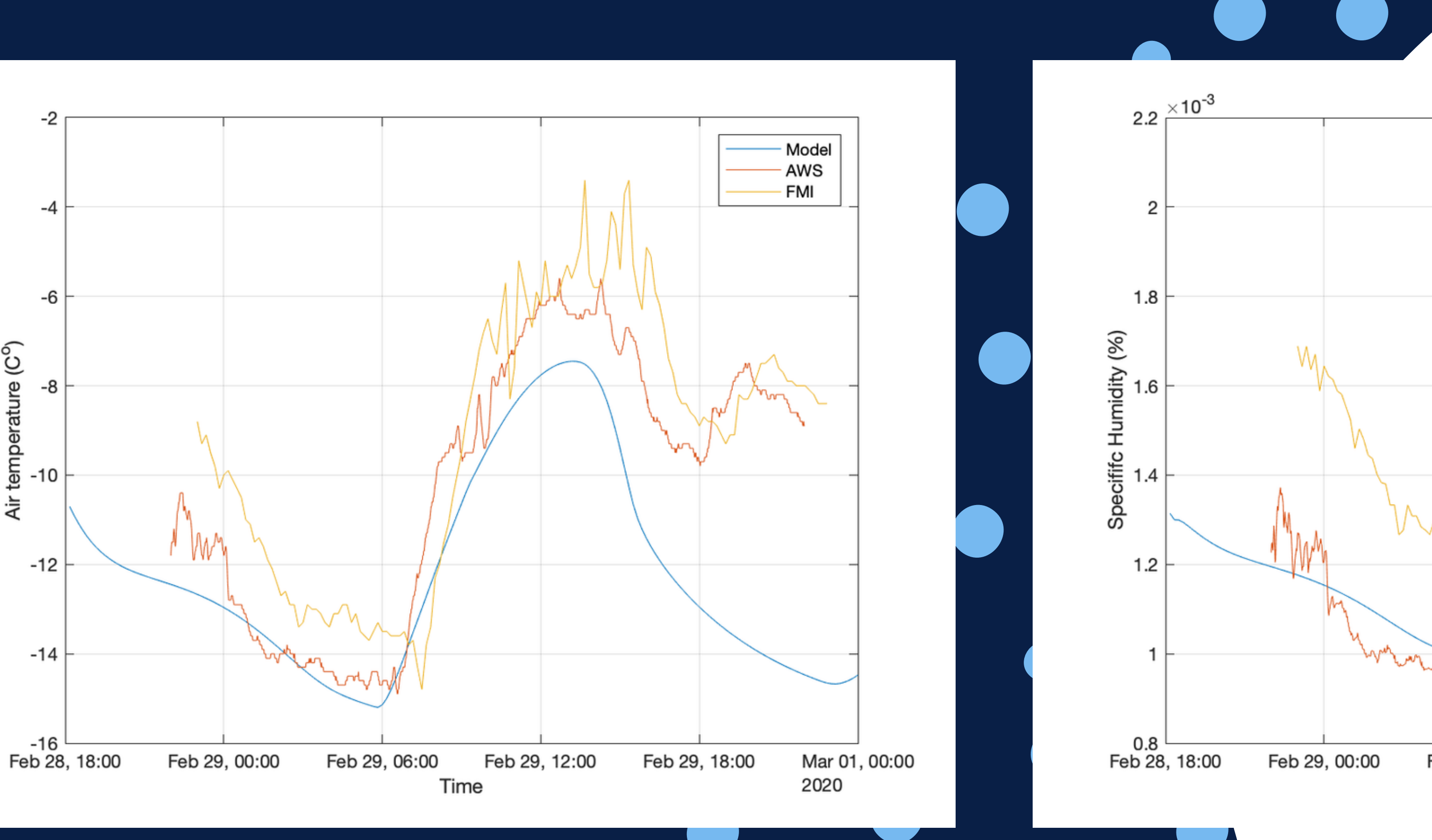

- THE WRF SCM WAS INITIALIZED WITH $\because \because \because \because$ THEDATA FROM UM ICM MODEL AND $\because \because \because \therefore$

$\because \because \because \because \because$ ADJUSTED TO THE CONDITIONS IN

$\because \because \because \because$ HAILUOTO (SEA ICE TEMPERATURE, ICE THICKNESS)

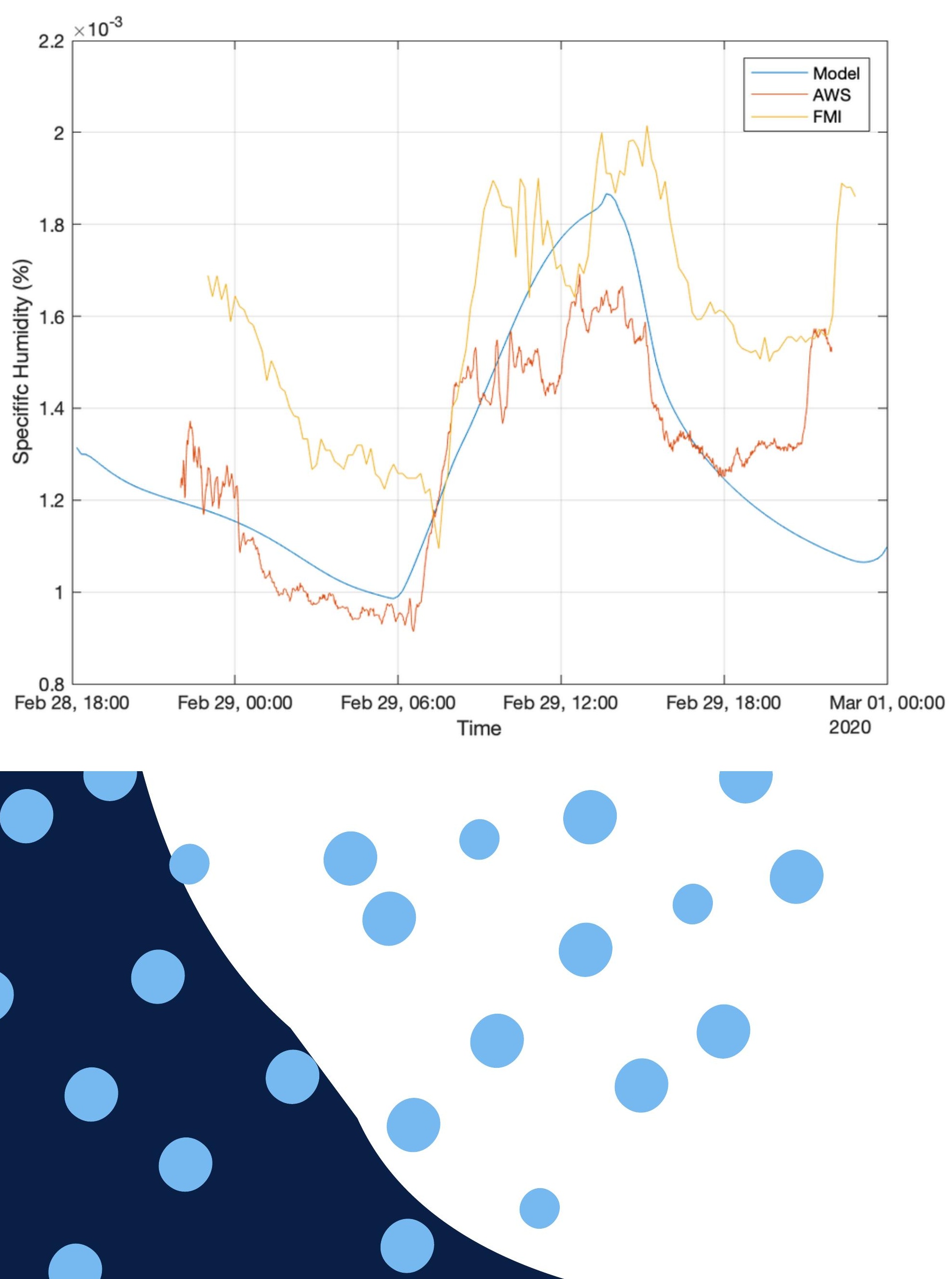




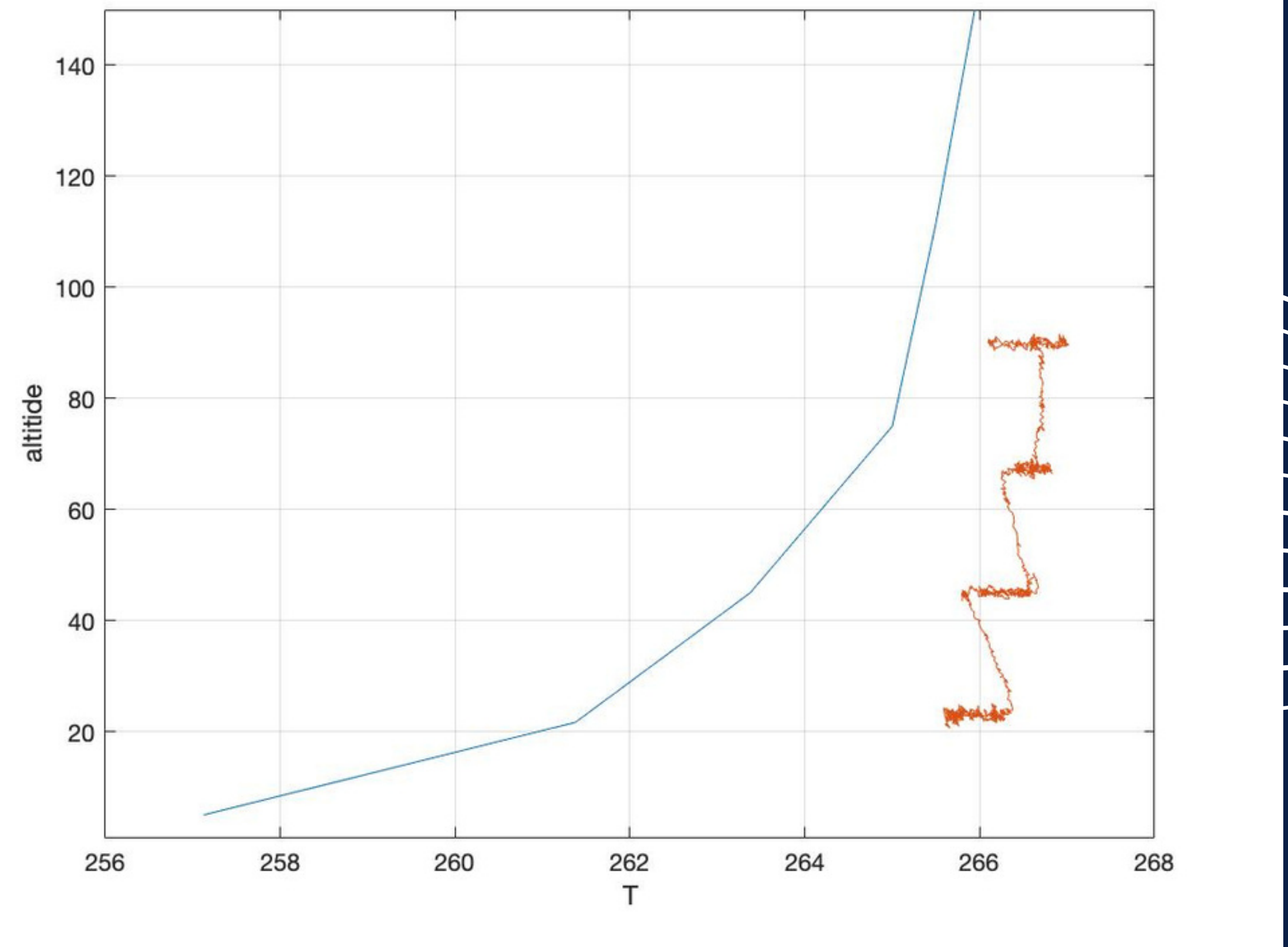

\section{Unnderestimated}

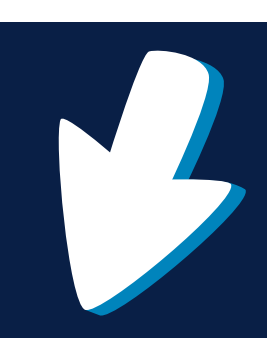
temperature, with negative bias. the UAV measurements (red line).

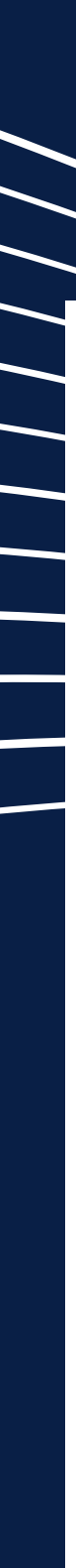

(3)

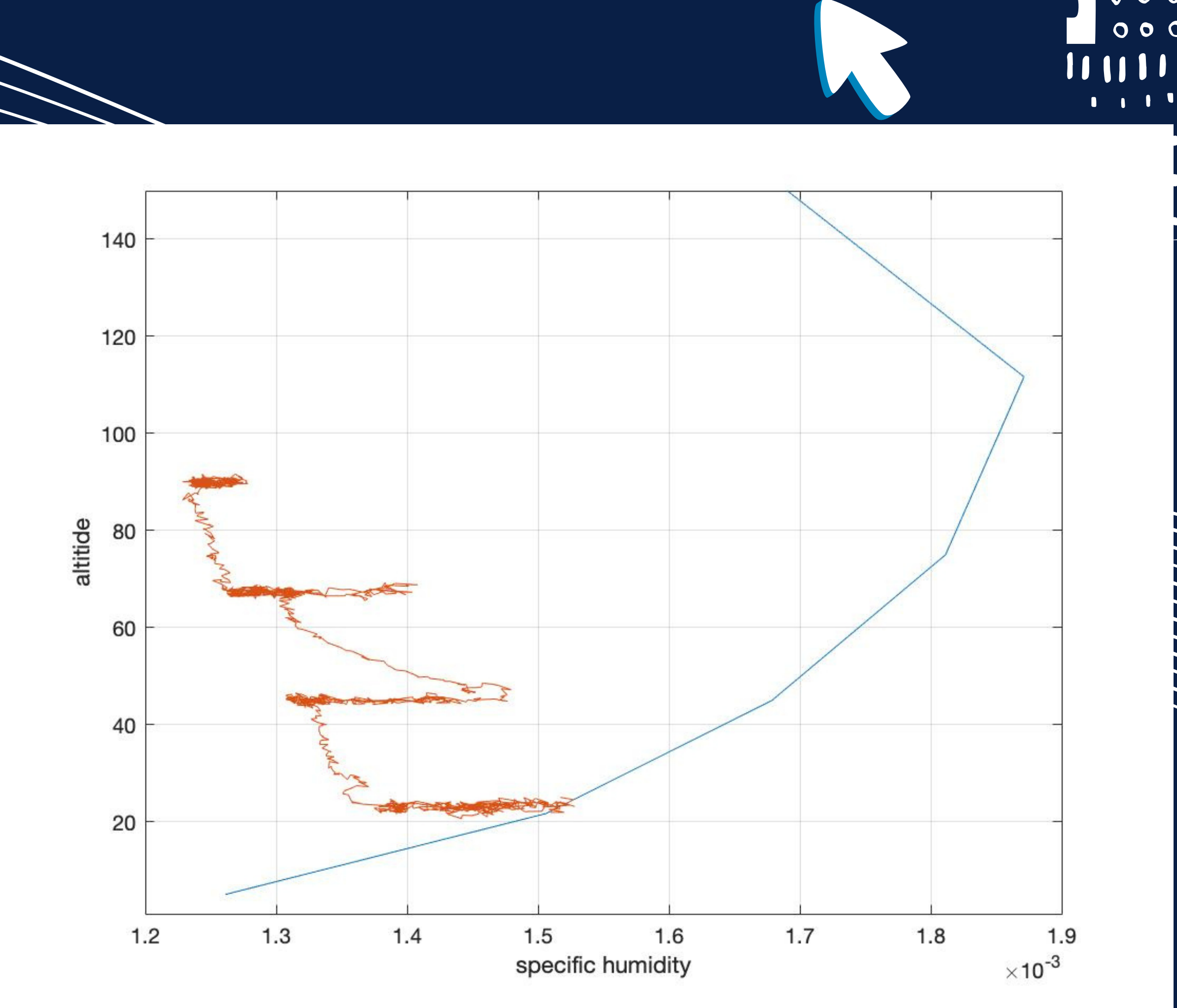




\section{FUTURE}

- ARTICLE DESCRIBING IN DETAIL THE MEASUREMENTS AND DATASETS CREATED DURING HAOS CAMPAIGN IS CURRENTLY UNDER PREPARATION.

- DATA ANALYSIS AND CONCLUSIONS WILL BE PUBLISHED AND PRESENTED LATER IN 2020.

- NeXt yeaR We plaN to RePeat the CAMPAIGN IN THE SAME LOCATION.
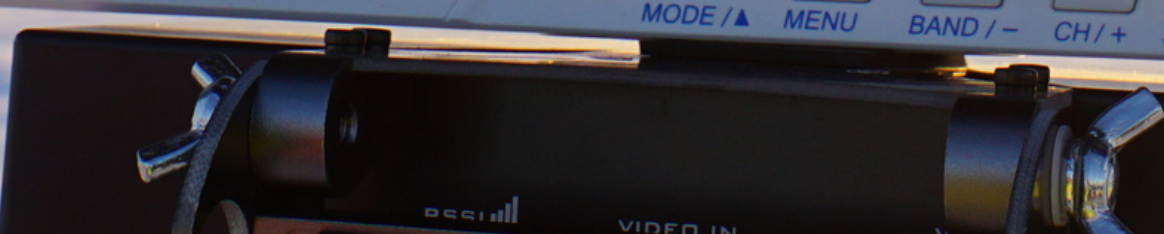

DATASET: Winter atmospheric boundary layer observations over sea ice in the coastal zone of the Bothnian Bay (Baltic Sea).

Wenta, Marta; Brus, David; Doulgeris, Konstantinos-Matthaios; Vakkari, Ville; Herman, Agnieszka

https://doi.org/10.1594/PANGAEA.918823

ARTICLE: Wenta, M., Brus, D., Doulgeris, K., Vakkari, V., and Herman, A.: Winter atmospheric boundary layer observations over sea ice in the coastal zone of the Bothnian Bay (Baltic Sea), Earth Syst. Sci. Data, Discuss., https://doi.org/10.5194/essd-2020-153, in review, 2020. 


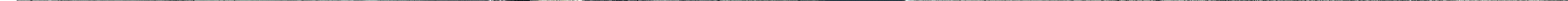

